\title{
INTRODUCTION: THE FIVE KEY TERMS OF DRAMATISM
}

What is involved, when we say what people are doing and why they are doing it? An answer to that question is the subject of this book. The book is concerned with the basic forms of thought which, in accordance with the nature of the world as all men necessarily experience it, are exemplified in the attributing of motives. These forms of thought can be embodied profoundly or trivially, truthfully or falsely. They are equally present in systematically elaborated metaphysical structures, in legal judgments, in poetry and fiction, in political and scientific works, in news and in bits of gossip offered at random.

We shall use five terms as generating principle of our investigation. They are: Act, Scene, Agent, Agency, Purpose. In a rounded statement about motives, you must have some word that names the act (names what took place, in thought or deed), and another that names the scene (the background of the act, the situation in which it occurred); also, you must indicate what person or kind of person (agent) performed the act, what means or instruments he used (agency), and the purpose. Men may violently disagree about the purposes behind a given act, or about the character of the person who did it, or how he did it, or in what kind of situation he acted; or they may even insist upon totally different words to name the act itself. But be that as it may, any complete statement about motives will offer some kind of answers to these five questions: what was done (act), when or where it was done (scene), who did it (agent), how he did it (agency), and why (purpose).

If you ask why, with a whole world of terms to choose from, we select these rather than some others as basic, our book itself is offered as the answer. For, to explain our position, we shall show how it can be applied.

Act, Scene, Agent, Agency, Purpose. Although, over the centuries, men have shown great enterprise and inventiveness in pondering matters of human motivation, one can simplify the subject by this pentad of key terms, which are understandable almost at a glance. They need 
never to be abandoned, since all statements that assign motives can be shown to arise out of them and to terminate in them. By examining them quizzically, we can range far; yet the terms are always there for us to reclaim, in their everyday simplicity, their almost miraculous easiness, thus enabling us constantly to begin afresh. When they might become difficult, when we can hardly see them, through having stared at them too intensely, we can of a sudden relax, to look at them as we always have, lightly, glancingly. And having reassured ourselves, we can start out again, once more daring to let them look strange and diffcult for a time.

In an exhibit of photographic murals (Road to Victory) at the Museum of Modern Art, there was an aerial photograph of two launches, proceeding side by side on a tranquil sea. Their wakes crossed and recrossed each other in almost an infinity of lines. Yet despite the intricateness of this tracery, the picture gave an impression of great simplicity, because one could quickly perceive the generating principle of its design. Such, ideally, is the case with our pentad of terms, used as generating principle. It should provide us with a kind of simplicity that can be developed into considerable complexity, and yet can be discovered beneath its elaborations.

We want to inquire into the purely internal relationships which the five terms bear to one another, considering their possibilities of transformation, their range of permutations and combinations-and then to see how these various resources figure in actual statements about human motives. Strictly speaking, we mean by a Grammar of motives a concern with the terms alone, without reference to the ways in which their potentialities have been or can be utilized in actual statements about motives. Speaking broadly we could designate as "philosophies" any statements in which these grammatical resources are specifically utilized. Random or unsystematic statements about motives could be considered as fragments of a philosophy.

One could think of the Grammatical resources as principles, and of the various philosophies as casuistries which apply these principles to temporal situations. For instance, we may examine the term Scene simply as a blanket term for the concept of background or setting in general, a name for any situation in which acts or agents are placed. In our usage, this concern would be "grammatical." And we move into matters of "philosophy" when we note that one thinker uses "God" as 
his term for the ultimate ground or scene of human action, another uses "nature," a third uses "environment," or "history," or "means of production," etc. And whereas a statement about the grammatical principles of motivation might lay claim to a universal validity, or complete certainty, the choice of any one philosophic idiom embodying these principles is much more open to question. Even before we know what act is to be discussed, we can say with confidence that a rounded discussion of its motives must contain a reference to some kind of background. But since each philosophic idiom will characterize this background differently, there will remain the question as to which characterization is "right" or "more nearly right."

It is even likely that, whereas one philosophic idiom offers the best calculus for one case, another case answers best to a totally different calculus. However, we should not think of "cases" in too restricted a sense. Although, from the standpoint of the grammatical principles inherent in the internal relationships prevailing among our five terms, any given philosophy is to be considered as a casuistry, even a cultural situation extending over centuries is a "case," and would probably require a much different philosophic idiom as its temporizing calculus of motives than would be required in the case of other cultural situations.

In our original plans for this project, we had no notion of writing a "Grammar" at all. We began with a theory of comedy, applied to a treatise on human relations. Feeling that competitive ambition is a drastically over-developed motive in the modern world, we thought this motive might be transcended if men devoted themselves not so much to "excoriating" it as to "appreciating" it. Accordingly, we began taking notes on the foibles and antics of what we tended to think of as "the Human Barnyard."

We sought to formulate the basic stratagems which people employ, in endless variations, and consciously or unconsciously, for the outwitting or cajoling of one another. Since all these devices had a "you and me" quality about them, being "addressed" to some person or to some advantage, we classed them broadly under the heading of a Rhetoric. There were other notes, concerned with modes of expression and appeal in the fine arts, and with purely psychological or psychoanalytic matters. These we classed under the heading of Symbolic.

We had made still further observations, which we at first strove uneasily to class under one or the other of these two heads, but which we 
were eventually able to distinguish as the makings of a Grammar. For we found in the course of writing that our project needed a grounding in formal considerations logically prior to both the rhetorical and the psychological. And as we proceeded with this introductory groundwork, it kept extending its claims until it had spun itself from an intended few hundred words into nearly 200,000 , of which the present book is revision and abridgement.

Theological, metaphysical, and juridical doctrines offer the best illustration of the concerns we place under the heading of Grammar; the forms and methods of art best illustrate the concerns of Symbolic; and the ideal material to reveal the nature of Rhetoric comprises observations on parliamentary and diplomatic devices, editorial bias, sales methods and incidents of social sparring. However, the three fields overlap considerably. And we shall note, in passing, how the Rhetoric and the Symbolic hover about the edges of our central theme, the Grammar.

A perfectionist might seek to evolve terms free of ambiguity and inconsistency (as with the terministic ideals of symbolic logic and logical positivism). But we have a different purpose in view, one that probably retains traces of its "comic" origin. We take it for granted that, insofar as men cannot themselves create the universe, there must remain something essentially enigmatic about the problem of motives, and that this underlying enigma will manifest itself in inevitable ambiguities and inconsistencies among the terms for motives. Accordingly, what we want is not terms that avoid ambiguity, but terms that clearly reveal the strategic spots at which ambiguities necessarily arise.

Occasionally, you will encounter a writer who seems to get great exaltation out of proving, with an air of much relentlessness, that some philosophic term or other has been used to cover a variety of meanings, and who would smash and abolish this idol. As a general rule, when a term is singled out for such harsh treatment, if you look closer you will find that it happens to be associated with some cultural or political trend from which the writer would dissociate himself; hence there is a certain notable ambiguity in this very charge of ambiguity, since he presumably feels purged and strengthened by bringing to bear upon this particular term a kind of attack that could, with as much justice, be brought to bear upon any other term (or "title") in philosophy, including of course the alternative term, or "title," that the writer would 
swear by. Since no two things or acts or situations are exactly alike, you cannot apply the same term to both of them without thereby introducing a certain margin of ambiguity, an ambiguity as great as the difference between the two subjects that are given the identical title. And all the more may you expect to find ambiguity in terms so "titular" as to become the marks of a philosophic school, or even several philosophic schools. Hence, instead of considering it our task to "dispose of" any ambiguity by merely disclosing the fact that it is an ambiguity, we rather consider it our task to study and clarify the resources of ambiguity. For in the course of this work, we shall deal with many kinds of transformation-and it is in the areas of ambiguity that transformations take place; in fact, without such areas, transformation would be impossible. Distinctions, we might say, arise out of a great central moltenness, where all is merged. They have been thrown from a liquid center to the surface, where they have congealed. Let one of these crusted distinctions return to its source, and in this alchemic center it may be remade, again becoming molten liquid, and may enter into new combinations, whereat it may be again thrown forth as a new crust, a different distinction. So that $\mathbf{A}$ may become non- $\mathrm{A}$. But not merely by a leap from one state to the other. Rather, we must take A back into the ground of its existence, the logical substance that is its causal ancestor, and on to a point where it is consubstantial with non-A; then we may return, this time emerging with non- $A$ instead.

And so with our five terms: certain formal interrelationships prevail among these terms, by reason of their role as attributes of a common ground or substance. Their participation in a common ground makes for transformability. At every point where the field covered by any one of these terms overlaps upon the field covered by any other, there is an alchemic opportunity, whereby we can put one philosophy or doctrine of motivation into the alembic, make the appropriate passes, and take out another. From the central moltenness, where all the elements are fused into one togetherness, there are thrown forth, in separate crusts, such distinctions as those between freedom and necessity, activity and passiveness, coöperation and competition, cause and effect, mechanism and teleology.

Our term, "Agent," for instance, is a general heading that might, in a given case, require further subdivision, as an agent might have his act modified (hence partly motivated) by friends (co-agents) or enemies 
(counter-agents). Again, under "Agent" one could place any personal properties that are assigned a motivational value, such as "ideas," "the will," "fear," "malice," "intuition," "the creative imagination." A portrait painter may treat the body as a property of the agent (an expression of personality), whereas materialistic medicine would treat it as "scenic," a purely "objective material"; and from another point of view it could be classed as an agency, a means by which one gets reports of the world at large. Machines are obviously instruments (that is, Agencies); yet in their vast accumulation they constitute the industrial scene, with its own peculiar set of motivational properties. War may be treated as an Agency, insofar as it is a means to an end; as a collective Act, subdivisible into many individual acts; as a Purpose, in schemes proclaiming a cult of war. For the man inducted into the army, war is a Scene, a situation that motivates the nature of his training; and in mythologies war is an Agent, or perhaps better a super-agent, in the figure of the war god. We may think of voting as an act, and of the voter as an agent; yet votes and voters both are hardly other than a politician's medium or agency; or from another point of view, they are a part of his scene. And insofar as a vote is cast without adequate knowledge of its consequences, one might even question whether it should be classed as an activity at all; one might rather call it passive, or perhaps sheer motion (what the behaviorists would call a Response to a Stimulus).

Or imagine that one were to manipulate the terms, for the imputing of motives, in such a case as this: The hero (agent) with the help of a friend (co-agent) outwits the villain (counter-agent) by using a file (agency) that enables him to break his bonds (act) in order to escape (purpose) from the room where he has been confined (scene). In selecting a casuistry here, we might locate the motive in the agent, as were we to credit his escape to some trait integral to his personality, such as "love of freedom." Or we might stress the motivational force of the scene, since nothing is surer to awaken thoughts of escape in a man than a condition of imprisonment. Or we might note the essential part played by the co-agent, in assisting our hero to escape-and, with such thoughts as our point of departure, we might conclude that the motivations of this act should be reduced to social origins.

Or if one were given to the brand of speculative enterprise exemplified by certain Christian heretics (for instance, those who worshipped 
Judas as a saint, on the grounds that his betrayal of Christ, in leading to the Crucifixion, so brought about the opportunity for mankind's redemption) one might locate the necessary motivational origin of the act in the counter-agent. For the hero would not have been prodded to escape if there had been no villain to imprison him. Inasmuch as the escape could be called a "good" act, we might find in such motivational reduction to the counter-agent a compensatory transformation whereby a bitter fountain may give forth sweet waters. In his AntiDühring Engels gives us a secular variant which no one could reasonably call outlandish or excessive:

It was slavery that first made possible the division of labour between agriculture and industry on a considerable scale, and along with this, the flower of the ancient world, Hellenism. Without slavery, no Greek state, no Greek art and science; without slavery, no Roman Empire. But without Hellenism and the Roman Empire as a basis, also no modern Europe.

We should never forget that our whole economic, political and intellectual development has as its presupposition a state of things in which slavery was as necessary as it was universally recognized. In this sense we are entitled to say: Without the slavery of antiquity, no modern socialism.

Pragmatists would probably have referred the motivation back to a source in agency. They would have noted that our hero escaped by using an instrument, the file by which he severed his bonds; then in this same line of thought, they would have observed that the hand holding the file was also an instrument; and by the same token the brain that guided the hand would be an instrument, and so likewise the educational system that taught the methods and shaped the values involved in the incident.

True, if you reduce the terms to any one of them, you will find them branching out again; for no one of them is enough. Thus, Mead called his pragmatism a philosophy of the act. And though Dewey stresses the value of "intelligence" as an instrument (agency, embodied in "scientific method"), the other key terms in his casuistry, "experience" and "nature," would be the equivalents of act and scene respectively. We must add, however, that Dewey is given to stressing the overlap of these two terms, rather than the respects in which they are distinct, as he proposes to "replace the traditional separation of nature 
and experience with the idea of continuity." (The quotation is from Intelligence and the Modern World.)

As we shall see later, it is by reason of the pliancy among our terms that philosophic systems can pull one way and another. The margins of overlap provide opportunities whereby a thinker can go without a leap from any one of the terms to any of its fellows. (We have also likened the terms to the fingers, which in their extremities are distinct from one another, but merge in the palm of the hand. If you would go from one finger to another without a leap, you need but trace the tendon down into the palm of the hand, and then trace a new course along another tendon.) Hence, no great dialectical enterprise is necessary if you would merge the terms, reducing them even to as few as one; and then, treating this as the "essential" term, the "causal ancestor" of the lot, you can proceed in the reverse direction across the margins of overlap, "deducing" the other terms from it as its logical descendants.

This is the method, explicitly and in the grand style, of metaphysics which brings its doctrines to a head in some over-all title, a word for being in general, or action in general, or motion in general, or development in general, or experience in general, etc., with all its other terms distributed about this titular term in positions leading up to it and away from it. There is also an implicit kind of metaphysics, that often goes by the name of No Metaphysics, and aims at reduction not to an overall title but to some presumably underlying atomic constituent. Its vulgar variant is to be found in techniques of "unmasking," which would make for progress and emancipation by applying materialistic terms to immaterial subjects (the pattern here being, " $\mathrm{X}$ is nothing but $\mathrm{Y}$," where $\mathrm{X}$ designates a higher value and $\mathrm{Y}$ a lower one, the higher value being thereby reduced to the lower one).

The titular word for our own method is "dramatism," since it invites one to consider the matter of motives in a perspective that, being developed from the analysis of drama, treats language and thought primarily as modes of action. The method is synoptic, though not in the historical sense. A purely historical survey would require no less than a universal history of human culture; for every judgment, exhortation, or admonition, every view of natural or supernatural reality, every intention or expectation involves assumptions about motive, or cause. Our work must be synoptic in a different sense: in the sense that it offers a 
system of placement, and should enable us, by the systematic manipulation of the terms, to "generate," or "anticipate" the various classes of motivational theory. And a treatment in these terms, we hope to show, reduces the subject synoptically while still permitting us to appreciate its scope and complexity.

It is not our purpose to import dialectical and metaphysical concerns into a subject that might otherwise be free of them. On the contrary, we hope to make clear the ways in which dialectical and metaphysical issues necessarily figure in the subject of motivation. Our speculations, as we interpret them, should show that the subject of motivation is a philosophic one, not ultimately to be solved in terms of empirical science. 
